\title{
Pengaruh Penyuluhan Kelas Ibu Hamil Terhadap Tingkat Pengetahuan Masyarakat Di Wilayah Kerja Puskesmas Seyegan Yogyakarta
}

\author{
Lina Handayani ${ }^{1}$, Atikah Nurhesti ${ }^{2}$, Chayanita Sekar Wijaya ${ }^{3}$, Reni Maelan ${ }^{4}$, \\ Moh. Jamko 5 \\ ${ }^{1}$ Dosen Pasca Sarjana Kesehatan Masyarakat, Universitas Ahmad Dahlan, Yogyakarta \\ 2,3,4,5Pasca Sarjana Kesehatan Masyarakat, Universitas Ahmad Dahlan, Yogyakarta \\ *)Email: chayanitasekarw@gmail.com
}

\begin{abstract}
Abtrak. Masih tingginya angka kematian ibu dan bayi masih menjadi masalah kesehatan di Indonesia. Sehingga perlunya penyuluhan dan edukasi untuk mengurangi masalah tersebut. Salah satunya dengan melaksanakan dan meingkatkan kunjungan pada kelas ibu hamil. Dengan mengadakan kelas ibu hamil dapat mengurangi risiko kematian ibu dan bayi dengan mengetahui risiko kehamilan dan upaya pencegahan serta penanggulangan komplikasi saat persalinan. Tujuan penelitian ini adalah untuk mengetahui pengaruh penyuluhan kelas ibu terhadap peningkatan pengetahuan masyarakat di wilayah kerja Puskesmas Seyegan Yogyakarta. Jenis penelitian ini menggunakan pendekatan deskriptif kuantitatif dengan rancangan penelitian one group pretestposttest. Dengan pengambilan sampel menggunakan total sampling dan diperoleh sampel sebanyak 42 orang dari kader, ibu hamil dan ayah ASI. Hasil penelitian menunjukkan bahwa masyarakat mengalami peningkatan pengetahuan sebanyak 26 orang $(61,90 \%)$ dengan rata-rata peningkatan pengetahuan sebesar 24,60 dalam kategori pengetahuan baik setelah dilakukan penyuluhan mengenai kelas ibu. Dapat disimpulkan bahwa penyuluhan berpengaruh terhadap peningkatan pengetahuan masyarakat mengenai kelas ibu hamil di wilayah kerja Puskesmas Seyegan Yogyakarta.
\end{abstract}

Kata Kunci: Kelas Ibu hamil, Pengetahuan, Penyuluhan

\section{The Effect of Counseling on Pregnant Women Classes on Community Knowledge Level in the Work Area of Seyegan Yogyakarta Health Center}

Abtract. The high rate of maternal and infant mortality is still a health problem in Indonesia. So the need for counseling and education to reduce these problems. One of them is by carrying out and increasing visits to classes of pregnant women. By holding classes for pregnant women can reduce the risk of maternal and infant mortality by knowing the risks of pregnancy and efforts to prevent and manage complications during childbirth. The purpose of this study was to determine the effect of maternal class counseling on increasing community knowledge in the work area of Yogyakarta Seyegan Health Center. This type of research uses a quantitative descriptive approach with one group pretest-posttest design. By sampling using a total sampling and obtained a sample of 42 people from cadres, pregnant women and ASI fathers. The results showed that the community experienced an increase in knowledge of 26 people $(61.90 \%)$ with an average increase of knowledge of 24.60 in the category of good knowledge after counseling about the mother's class. It can be concluded that counseling has an effect on increasing public knowledge about classes of pregnant women in the working area of Yogyakarta Seyegan Health Center.

Keywords: Class of Pregnant Women, Knowledge, Counseling 


\section{Pendahuluan}

Tujuan dari pembangunan kesehatan indonesia adalah untuk meningkatkan kesadaran, kemauan dan kemampuan kemauan, dan kemampuan hidup sehat bagi setiap orang agar terwujud derajat kesehatan masyarakat yang setinggi- tingginya, sebagai investasi bagi pembangunan sumber daya manusia yang produktif secara sosial dan ekonomis. Menurut Renstra tahun 20152019 pembangunan kesehatan dengan program Indonesia sehat dengan salah satu sasarannya adalah meningkatkan status kesehatan dan gizi ibu dan anak. dalam Renstra, angka kematian ibu menurun dari 359 per 100.000 kelahiran hidup menjadi 306 per 100.000 kelahiran ibu. Kemudian angka kematian bayi menurun dari 32 menjadi 24 per 1000 kelahiran hidup. Sasaran pembangunan kesehatan yang akan dicapai pada tahun 2025 adalah meningkatnya derajat kesehatan masyarakat yang ditunjukkan oleh meningkatnya Umur Harapan Hidup, menurunnya Angka Kematian Bayi, menurunnya Angka Kematian Ibu, menurunnya prevalensi gizi kurang pada balita (Kemenkes RI, 2015).

Angka kematian ibu dan bayi yang masih tinggi menjadi masalah dalam upaya pembangunan kesehatan, maka kementerian kesehatan membuat upaya kesehatan yang terdiri dari kegiatan promotif dan preventif dengan mengadakan kelas ibu hamil. Kelas ibu hamil merupakan upaya bidang promkes bagian KIA, Promosi kesehatan atau promkes merupakan program yang diharapkan dapat merubah perilaku masyarakat secara menyeluruh dalam konteks masyarakat baik perubahan perilaku maupun perubahan lingkungannya (Depkes RI, 2009b; Sari, $\mathrm{M}$ and Cahyo, 2014).
Depkes (2009) mengatakan bahwa kehamilan merupakan masa dimana janin berada dalam rahim perempuan. Dalam masa masa kehamilan ini diawali dengan pembuahan dari sel sperma lakilaki dengan sel telur yang dihasilkan oleh indung telur. Kemudian masuk pada masa pembuahan dengan terbentuknya janin sebagai tanda kehidupan baru yang tumbuh dalam rahim ibu. Kehamilan dan persalinan adalah hal fisiologis dan berisiko. Untuk mencegah risiko ini maka bidan melakukan Asuhan kebidanan dengan melakukan deteksi dini terhadap komplikasi dan penyakit selama kehamilan. Asuhan ini dilakukan dengan cara penyuluhan mengenai kesehatan ibu dan anak baik individual maupun per kasus yang dilakukan saat pemeriksaan kandungan di posyandu. Namun, terdapat kelemahan dimana faktor pengetahuan tentang masalah kesehatan terbatas dan tidak terkoordinir saat konsultasi, sehingga ibu hanya mendapat pengetahuan dari petugas saja. Sedangkan rencana kerja, penyuluhan tidak terencana, terjadwal serta tidak berkesinambungan (Depkes RI, 2009a; Retnaningtyas, 2017).

Pengetahuan yang rendah yang dimiliki oleh ibu hamil memiliki risiko kehamilan yang lebih tinggi. Hal ini disebabkan karena pengetahuan yang rendah yang dimiliki oleh ibu tidak dapat membuat ibu untuk mengambil keputusan lebih cepat dan tepat terhadap kesehatan ibu. Sehingga perlu metode yang berbeda untuk meningkatkan pengetahuan ibu, hal ni yang membuat Dinas Kesehatan mengeluarkan kebijakan untuk membuat kegiatan kelompok belajar ibu hamil. Dengan dibentuknya kelas ibu hamil ini betujuan untuk meningkatkan keteramilan dan pengetahuan ibu, anak serta keluarga (Retnaningtyas, 2017). Kelas ibu hamil adalah sarana bagi ibu hamil untuk 
belajar kesehatan secara bersama dengan tatap muka dalam kelompok dengan tujuan dapat meningkatkan pengetahuan, dan merubah perilaku dan sikap ibu hamil dalam memahami kehamilan perubahan tubuh selama kehamilan, perawatan kehamilan, persalinan, perawatan nifas, KB pasca persalinan, perawatan bayi baru lahir, mitos, penyakit menular dan akte kelahiran (Depkes RI, 2014).

Berdasarkan uraian tersebut, peneliti ingin meneliti tentang pengaruh penyuluhan kelas ibu hamil terhadap peningkatan pengetahuan masyarakat di wilayah kerja Puskesmas Seyegan, Desa Margokaton, Kabupaten Sleman. Penelitian ini dilakukan dengan mengadakan penyuluhan dan edukasi mengenai pengetahuan dasar mengenai kelas ibu hamil dan hal penting yang berkaitan dengan ibu hamil dengan sasaran penyuluhan adalah para kader posyandu, ibu hamil dan bapak pendamping ASI.

\section{Metode}

Penelitian ini dilakukan dengan pendekatan deskriptif kuantitatif dengan rancangan penelitian one group pretestposttest. Kemudian, populasi penelitian yaitu Kader, bapak pendamping asi, ibu hamil Desa margokaton di wilayah kerja puskesmas seyegan, kabupaten sleman. Sampel diambil dengan menggunakan teknik total sampling dan jumlah sampel sebanyak 42 orang setiap kelompok. Penelitian ini dilakukan dengan menggunakan kuesioner sebagai instrument penelitian. Kemudian, data dianalisis secara deskriptif dan disajikan dalam bentuk tabel.

\section{Hasil Penelitian}

Berdasarkan penelitian yang telah dilakukan, didapatkan hasil sebagai berikut:

Tabel 1. Distribusi Frekuensi Peningkatan Pengetahuan Tentang Kelas Ibu Di Wilayah Kerja Puskesmas

\begin{tabular}{ccccc}
\multirow{2}{*}{$\begin{array}{c}\text { Tingkat } \\
\text { Pengetahuan }\end{array}$} & \multicolumn{2}{c}{ Pretest } & \multicolumn{2}{c}{ Posttest } \\
\cline { 2 - 5 } & f & \% & f & $\%$ \\
\hline Baik & 24 & 57,1 & 26 & 61,9 \\
Kurang & 18 & 42,9 & 16 & 38,1 \\
\hline Total & 42 & 100 & 42 & 100 \\
\hline Mean & 21,83 & \multicolumn{2}{c}{24,6} \\
\hline Seyegan, & Kabupaten & \multicolumn{2}{c}{ Sleman, } \\
Yogyakarta & & \multicolumn{2}{l}{}
\end{tabular}

Sumber: Data Primer, 2020

Berdasarkan hasil penelitian pada Tabel diatas, menunjukkan bahwa lebih dari setengah responden $61,9 \%$ (26 orang) memiliki pengetahuan yang baik mengenai kelas ibu hamil. Sedangkan untuk responden dengan tingkat pengetahuan kurang menurun menjadi $38,1 \%$ dari sebelum penyuluhan dan edukasi sebeser $42,9 \%$. Sementara itu terdapat perbedaan rata-rata pengetahuan sebelum penyuluhan dan setelah penyuluhan. Dimana rata-rata pengetahuan baik saat pretest sebesar 21,83 dan mengalami peningkatan pengetahuan setelah dilakukan penyuluhan sebesar 24,60. Sehingga dapat dikatakan bahwa penyuluhan mengenai kelas ibu hamil berpengaruh terhadap peningkatan pengetahuan masyarakat di wilayah kerja Puskesmas Seyegan, Yogyakarta.

\section{Pembahasan}

Hasil penelitian yang telah dilakukan dapat dikatakan bahwa penyuluhan yang dilakukan di wilayah kerja Puskesmas Seyegan Yogyakarta 
berpengaruh terhadap peningkatan pengetahuan masyarakatnya mengenai program kelas ibu hamil. Sasaran penelitian ini adalah kader-kader puskesmas, ibu hamil dan ayah asi. Setelah dilakukan penyuluhan, pengetahuan masyarakat meningkat dalam kategori baik dan lebih dari setengah responden mengalami peningkatan pengetahuan. Penyuluhan dan edukasi yang dilakukan merupakan pengetahuan dasar tentang program kelas ibu hamil, dasar kelas ibu hamil.

Menurut Notoatmodjo (2003) hasil tahu dan penginderaan dari objek tertentu yang dilakukan seseorang disebut dengan pengetahuan. Penginderaan yang dilakukan melalui panca indera manusia meliputi pendengaran penglihatan, rasa, raba dan penciuman. Dan pengetahuan manusia sebagian besar diperoleh dari penginderaan melalui mata dan telinga. Kemudian, selain dengan penginderaan, pengetahuan juga dipengaruhi oleh informasi yang diperoleh dari berbagai sumber pengetahuan. Semakin banyak informasi yang diperoleh seseorang maka semakin luas pengetahuan yang dimiliki (Notoatmodjo, 2003).

Penelitian yang dilakukan menunjukkan bahwa penyuluhan dapat meningkatkan pengetahuan kader, ayah asi terutama ibu hamil. Kelas ibu penting diketahui dan diikuti oleh ibu hamil karena dalam kelas ibu hamil dalam kelas ibu hamil terdapat kegiatan yang membahas tentang materi buku KIA kemudian diskusi dan tukar pengalaman dari sesama ibu hamil, suami dan keluarga serta petugas kesehatan. Sehingga ibu hamil dapat memahami masa kehamilan hingga persalinan dan perawatan bayi dengan optimal (Depkes RI, 2014).
Penelitian

sebelumnya mengatakan bahwa bagi ibu hamil kelas ibu memiliki manfaat yang besar dalam meningkatkan pengetahuan ibu dan mengubah perilaku dan sikap ibu untuk memahami teknik meneran dalam proses persalinan. Rendahnya pengetahuan ibu akan berakibat pada pengambilan keputusan yang terlambat. Sehingga dengan mengikuti kelas ibu, diharapkan ibu hamil dapat mengambil keputusan dengan tepat dan cepat pada masa kehamilan dan dapat melakukan proses persalinan dengan lancar dan aman (Novadela and Supriatiningsih, 2013). Selain itu, menurut penelitian Putri (2018) bahwa sebanyak $66,7 \%$ ibu hamil memiliki perubahan perilaku dengan mengunjungi kelas ibu hamil dan sebanyak $26,6 \%$ ibu mengalami peningkatan pengetahuan yang baik tentang kelas ibu. Hal ini didukung dengan penyampaian informasi kesehatan yang diberikan secara rutin oleh petugas kesehatan. Pelaksanaan kelas ibu hamil yang diadakan secara rutin setiap minggu dengan materi yang berbeda menjadi hal yang menarik sehingga ibu hamil tertarik untuk datang setiap minggu untuk mengikuti kelas ibu hamil dmei menjaga kesehatan pada masa kehamilannya (Putri and Astutik, 2018).

Ibu hamil merupakan sasaran utama dari kelas hamil. Namun, sasaran lain dari kegiatan ini adalah suami/keluarga. Dengan adanya suami atau keluarga diharapkan terjadinya interaksi dengan sesama anggota kelas ibu hamil dengan suami atau keluarga yang dapat ikut serta minimal 1 kali pertemuan pada materi yang penting. Peran suami atau ayah ASI sangat membantu memotivasi ibu dalam pemberian ASI esklusif pada bayi baru lahir dengan mengikuti kelas ibu hamil. Suami yang mendukung ibu untuk 
memberikan ASI sangat berperan penting sehingga meningkatkan kepercayaan diri ibu dan memicu produk ASI meningkat dan berlimpah serta meningkatkan kenyamanan dalam menjalani peran ibu untuk mengurangi risiko terjadinya postpartum blues (Evareny, Hakimi and Padmawati, 2010; Depkes RI, 2014; Nurafifah, 2016; Andayani, Emilia and Ismail, 2017; Damayanti, 2018).

Penelitian ini menunjukkan bahwa terdapat perbedaan pengetahuan masyarakat sebelum dan sesudah mengikuti penyuluhan kelas ibu hamil, sehingga penyuluhan yang dilakukan efektif untuk meningkatkan pengetahuan masyarakat. Hasil penelitian ini sejalan dengan penelitian yang dilakukan oleh Eliana (2012) yang menunjukkan bahwa terdapat perbedaan pengetahuan ibu hamil sebelum dan sesudah mengikuti kelas ibu hamil di Puskesmas Wangon II. Kemudian pengetahuan yang semakin tinggi akan meempengaruhi keikutsertaan ibu hamil diikuti dengan dukungan suami untuk mengikuti kelas ibu hamil (Arfiah Eliana and Fridayanti, 2012; Septiani, 2013). Sejalan dengan penelitan yang dilakukan Astuti (2020) mengatakan bahwa pengetahuan responden semakin baik setelah dilakukan treatment pada kelompok pretest dan posttest sebanyak 70,3\% (Astuti et al., 2020)

Dengan mengikuti kelas ibu hamil baik kader, ibu hamil dan ayah ASI dapat meningkatkan pengetahuan mengenai pentingnya kelas ibu, terutama bagi ibu hamil dapat mengetahui risiko dan deteksi dini risiko kehamilan, serta upaya dalam pencegahan komplikasi saat persalinan dan meningkatkan kewaspadaan yang lebih baik serta mengetahui upaya pencegahan dan penanggulangannya. Dengan demikian perlunya koordinasi dari penyedia layanan kesehatan dan pemerintah serta sosialisasi rutin pada masyarakat mengenai program kelas hamil (Puspitasari, 2012; Kusbandiyah, 2013; Fibriana and Azinar, 2016; Iswari, 2017).

\section{Kesimpulan}

Dapat disimpulkan bahwa terdapat terdapat pengaruh sebelum dan sesudah penyuluhan mengenai kelas ibu hamil terhadap peningkatan pengetahuan kader, ibu hamil dan ayah ASI di wilayah kerja Puskesmas Seyegan, Kabupaten Sleman, Yogyakarta sebesar $61,90 \%$ atau sebanyak 26 orang memiliki peningkatan pengetahuan yang lebih baik dengan rata-rata pengetahuan setelah penyuluhan sebesar 24,80 .

\section{Daftar Pustaka}

Andayani, D., Emilia, O. And Ismail, D. (2017) 'Peran Program Kelas Ibu Hamil Terhadap Pelaksanaan Asi Eksklusif Di Gunung Kidul', Berita Kedokteran Masyarakat, 33(7), P. 317. Doi: 10.22146/Bkm.18048.

Arfiah Eliana And Fridayanti, W. (2012) 'Perbedaan Rerata Pengetahuan Ibu Hamil Sebelum Dan Sesudah Mengikuti Kelas Ibu Hamil Di Puskesmas Wangon Ii Kabupaten Banyumas Tahun 2012', Bidan Prada : Jurnal Ilmiah Kebidanan, 3(2), Pp. 54-62.

Astuti, D. P. Et Al. (2020) 'Pendidikan Kesehatan Terhadap Tingkat Pengetahuan Deteksi Tanda Bahaya Kehamilan Dan Persalinan', Jurnal Ilmiah Kesehatan, XIII(I), Pp. 5-10.

Damayanti, D. J. N. (2018) 'FaktorFaktor Yang Berhubungan Dengan Motivasi Ibu Hamil Mengikuti Kelas Ibu Hamil Di Wilayah Kerja Puskesmas Sukoharjo Kabupaten Sukoharjo', Naskah Publikasi.

Depkes RI (2009a) Pedoman Pelaksanaan 
Kelas Ibu Hamil. Jakarta: Departemen Kesehatan RI.

Depkes Ri (2009b) Pelatihan Kelas Ibu

Hamil. Jakarta: Departemen

Kesehatan RI.

Depkes RI (2014) Pedoman Pelaksanaan

Kelas Ibu Hamil. Jakarta:

Departemen Kesehatan RI.

Evareny, L., Hakimi, M. And

Padmawati, R. S. (2010) 'Peran

Ayah Dalam Praktik Menyusui',

Jurnal Kebijakan Kesehatan

Indonesia, 26(4), Pp. 187-195.

Fibriana, A. I. And Azinar, M. (2016)

'Model Kelas Ibu Hamil Untuk

Pemetaan Risiko Kehamilan Dan

Pencegahan

Komplikasi

Persalinan', Abdimas, 20(1), Pp. 11-

18.

Iswari, I. (2017) 'Description Of Maternal

Mother 'S Knowledge Toward

Maternal Class In The Working

Area Of Nusa Indah Public Health

Center Bengkulu 2016', Journal Of

Midwifery, 5(1), Pp. 9-13.

Kemenkes RI (2015) Rencana Strategis

Kementerian Kesehatan Tahun

2015-2019. Keputusan Menteri

Kesehatan Republik Indonesia No.

Hk.02.02/Menkes/52/2015,

Kementerian Kesehatan RI.

Sekretariat Jenderal. Jakarta:

Kementerian Kesehatan RI.

Kusbandiyah, J. (2013) 'Analisis

Implementasi Program Kelas Ibu

Hamil Oleh Bidan Puskesmas Di

Kota Malang', Jurnal Ilmiah

Kesehatan Media Husada, 02(01),

Pp. 1-9.

Notoatmodjo, S. (2003) Pendidikan Dan

Perilaku Kesehatan. Jakarta:

Rineka Cipta.

Novadela, N. I. T. And Supriatiningsih (2013) 'Pengaruh Program Kelas Ibu Terhadap Pengetahuan Ibu Hamil Trimester Iii Tentang Teknik Meneran', Jurnal Kesehatan, Iv(2), Pp. 351-356.
Nurafifah, D. (2016) 'Ayah Asi (Breastfeeding Father) Terhadap Kejadian Postpartum Blues', Rakernas Aipkema 2016: Temu Ilmiah Hasil Penelitian Dan Pengabdian Masyarakat, Pp. 75-81.

Puspitasari, L. (2012) 'Gambaran Pelaksanaan Kelas Ibu Hamil Di Puskesmas Bangetayu Kota Semarang', Jurnal Kesehatan Masyarakat, 1(2), Pp. 1054-1060.

Putri, B. A. G. And Astutik, T. (2018) 'The Effect Of Pregnancy Class On Pregnant Womans Knowledge About Antenatal Care Using Community As Partner Approach In The Karangasem Hamlet Glagahwero Village Districts Panti Of Jember Regency', The Indonesian Journal of Health Science, 10(September), Pp. 145150.

Retnaningtyas, E. (2017) 'Pengaruh Pengetahuan Tentang Kelas Ibu Hamil Terhadap Perilaku Perawatan Kehamilan Pada Ibu Hamil Di Wilayah Kerja Puskesmas Nganjuk', Jurnal Edumidwifery, 1(1), Pp. 42-49.

Sari, R. P., M, S. B. And Cahyo, K. (2014) 'Description Of Implementation Of Pregnancy Class In Worked Area Of Public Health Centre Mranggen District Demak Regency', Jurnal Kesehatan Masyarakat (E-Journal), 2(3), Pp. 176-183.

Septiani, R. (2013) 'Pengetahuan, Sikap Ibu Hamil Dan Dukungan Suami Dengan Keikutsertaan Ibu Hamil Dalam Kelas Ibu Hamil Di Puskesmas Kota Metro Lampung', Jurnal Kesehatan, Iv(2), Pp. 408415. 